\title{
TERMIČKA KARAKTERIZACIJA NOVOG IZOLACIONOG MATERIJALA - IZORETEX ${ }^{1}$
}

Djordje Djordjević $^{2}$
Biljana Avramović
Dragoslav Stojić

УДК: 699.86:691.15

DOI:10.14415/konferencijaGFS 2015.003

Rezime: Gradjevinski klaster „Dundjer”, zajedno sa većim brojem svojih članica, učestvuje, kao vodeći partner, u projektu pod nazivom IZORETEX, koji ko-finansira Nacionalna agencija za regionalni razvoj. IZORETEX je projekat čiji je cilj da razvije novi termički, zvučni $i$ anti-vibracioni gradjevinski izolacioni materijal koji se bazira na reciklaži tekstilnog otpada u automobilskoj industriji. Predvidjeno istraživanje sadrži, pored ostalog, eksperimente sa toplotnim, zvučnim, vibracionim i protiv-zapaljivim osobinama ovog izolacionog materijala. Termički deo istraživanja sadrži numeričko modeliranje termičkog ponašanja materijala, pisanje koda za softverski model, kao i laboratorijsko testiranje toplotnih karakteristika. U ovom trenutku je testiranje materijala u toku i pretpostavlja se da će potvrditi prognozirane toplotne, akustičke $i$ anti-vibracione osobine projektovanog izolacionog materijala.

Ključne reči: industrijski otpad, tekstilni otpad, auto-tekstilni otpad, termička izolacija u gradjevinarstvu, energetska efikasnost.

\section{UVOD}

Glavni cilj projekta IZORETEKS je razvoj kompozitnog materijala koji se sastoji od izolacionih vlakana dobijenih reciklažom tekstilnog otpada dobijenog pri proizvodnji automobila, kao i posle eksploatacionog perioda. Taj novi materijal, pogodan za primenu na lakim gradjevinskim konstrukcijama, pokazuje unapredjene termičke karakteristike koje se zasnivaju na niskoj termičkoj provodnosti (visoka termička otpornost) i solidnoj termičkoj kapacitivnosti koja ublažava efekat velikih varijacija spoljašnje temperature.

\footnotetext{
${ }^{1}$ Istraživanje podržano Programom podrške razvoja inovativnih klastera 2014-2015.

${ }^{2}$ University of Niš, Faculty of Civil Engineering and Architecture, A. Medvedeva 14, Niš, tel: ++381 64156 36 76, e- mail: djoka@ni.ac.rs

${ }^{3}$ Biljana Avramović, Construction Cluster Dundjer, Niš, Rajićeva 30a, tel. ++381 18522 812, e-mail: KlasterDundjer@yahoo.com

${ }^{4}$ University of Niš, Faculty of Civil Engineering and Architecture, A. Medvedeva 14, Niš, tel. ++381 65217 0200, e-mail: Dragoslav.Stojic@gaf.ni.ac.rs
} 
Ovde je opisan simulacioni softverski modul koji istražuje osobine provodjenja toplote i toplotne performanse novog izolacionog materijala IZORETEKS. Svrha ovog softvera je da služi kao alatka za projektovanje i optimizaciju termičkih izolacionih sistema baziranih na recikliranom auto-tekstilnom otpadu. Štaviše, predvidjena je njegova integracija u opštiji softver koji je namenjen projektovanju energetski efikasnijih gradjevina. Prikaz je organizovan na sledeći način: prvo je dat kraći podsetnik matematičkih jednačina, koje modeliraju provodjenje toplote kroz jednoslojne i višeslojne sisteme. Navedene su takodje termo-fizičke osobine, potrebne za termičke simulacije. Drugo, navedene su različite numeričke šeme za rešavanje matematičkih jednačina. Softverski moduo je verifikovan pomoću dva reprezentativna test-slučaja: monolitni zid sa konstantnim karakteristikama i dvoslojni zid koji sadrži IZORETEKS. Konačno, softver se koristi za razmatranje efekata različitih parametara: tipa, količine i položaj IZORETEKS izolacije i unutrašnjih uslova. U eksperimentalnoj fazi izvršeno je uporedjenje različitih programa uz upotrebu našeg softverskog koda. Neka teoretska razmatranja rešavanja toplotne diferencijalne jednačine primenom Galerkinovog metoda primenjena su na jednostavnije primere. Eksperimenti su vršeni sa programskim sistemima MATLAB, MATHEMATICA, ANSYS, ENERGYPLUS i KnaufTerm.

\section{MATEMATIČKI MODEL: TOPLOTNA JEDNAČINA}

Cilj termičkog sofverskog modula koji je razvijen je da izračuna/simulira transport toplote u višeslojnom zidu. Za višeslojne zidove zgrada jednačina za prenos toplote je $u$ osnovi jednodimenzionalna (toplotni fluks normalan na površinu zida) u pravcu debljine zida i evolucija temperaturnog polja je definisana prelaznom toplotnom jednačinom:

gde su

$$
\rho c_{\mathrm{p}} \frac{\partial \mathrm{T}}{\partial \mathrm{t}}=\frac{\partial}{\partial \mathrm{x}}\left(\mathbf{k} \frac{\partial \mathrm{T}}{\partial \mathrm{x}}\right)
$$

$\mathbf{k}(\mathbf{T})$ : termička provodnost $(\mathrm{W} / \mathrm{m} \mathrm{K})$,

$\rho(\mathbf{T}):$ specifična gustina $\left(\mathrm{kg} / \mathrm{m}^{3}\right)$,

$\mathrm{c}_{\mathrm{p}}(\mathrm{T})$ : specifična toplotna kapacitivnost $(\mathrm{J} / \mathrm{kg} \mathrm{K})$,

termičko-fizičke osobine različitih materijala u svakom sloju zida. Ove karakteristike su potrebne kao ulazni podaci za rešavanje Toplotne jednačine (1), i radi toga one moraju da budu odredjene laboratorijskim merenjima. Treba uopšteno napomenuti da ove karakteristike variraju sa temperaturom. Ova jednačina mora biti dopunjena graničnim uslovima, temperaturama na unutrašnjoj i spoljašnjoj strani zida, kao i inicijalnim temperaturama (početni, inicijalni uslovi). 


\subsection{Granični uslovi}

Da bi se kompletirala postavka problema prenosa toplote, Toplotna jednačina (1) zahteva dva granična uslova na unutrašnjoj $i$ spoljnoj stranici zida $(x=0$ i $x=L$, respektivno), gde je $L$ debljina zida).

$\mathrm{Na}$ spoljašnjoj strani zida/fasade razmatra se uslov termičke konvekcije, koji karakteriše koeficijent prenosa toplote $\mathrm{h}_{\text {out }}$ izmedju temperature površine zida $\mathrm{i}$ spoljašnje temperature vazduha (videti (3) i (1)).

$$
\dot{\mathbf{q}}_{\text {out }}=-\left.\mathrm{k} \frac{\partial \mathrm{T}}{\partial \mathrm{x}}\right|_{\mathrm{s}=\mathrm{L}}=\mathrm{h}_{\text {out }}\left(\mathrm{T}_{\text {out }}(\mathrm{t})-\mathrm{T}(\mathrm{L}, \mathrm{t})\right)
$$

Da bi se predstavila oscilacija ambijetalne temperature tokom čitavog dana (noć i dan),

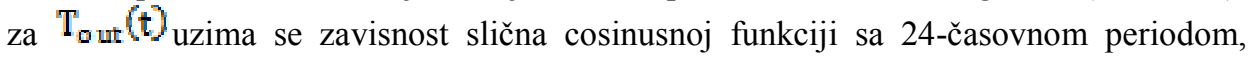
karakterisana maksimalnom temperaturom $\mathrm{T}_{\max }$ (koja se dostiže u podne) $\mathrm{i}$ minimalnom temperaturom $\mathrm{T}_{\text {smin }}$

$$
T_{\text {out }}(t)=\frac{T_{\max }+T_{m+1}}{2}+\frac{T_{m a x}-T_{m i n}}{2} \cos \left(\frac{2 \pi}{24}\left(\frac{t}{3600}-12\right)\right) .
$$

Tipične vrednosti za $\mathrm{T}_{\max } \quad \mathrm{i} \mathrm{T}_{\mathrm{min}}$ će zavisiti od klimatskih karakteristika geografske lokacije. U predhodnoj jednačini $t$ je dato u sekundama.

Na sličan način, na unutrašnjoj strani zida, uslov konvekcije, sa koeficijentom prenosa toplote $h_{\mathrm{in}}$ izmedju temperature unutrašnje površine zida $\mathrm{T}\left(\mathbf{0}_{\mathbf{s}} \mathrm{t}\right)$ i temperature unutrašnje prostorije $\mathrm{T}_{\mathrm{in}}$ se uzima kao

$$
\dot{\mathrm{q}}_{\mathrm{in}}=-\left.\mathrm{k} \frac{\partial \mathrm{T}}{\partial \mathrm{x}}\right|_{\mathrm{x}=0}=\mathrm{h}_{\mathrm{in}}\left(\mathrm{T}(\mathbf{0 , t})-\mathrm{T}_{\mathrm{in}}\right)
$$

Temperatura prostorije $\mathrm{T}_{\mathrm{in}}$ se uzima kao konstantna vrednost koja predstavlja kontrolisanu unutrašnju temperaturu pomoću KGH (HVAC) sistema. Iako se za obe površine uvode granični uslovi toplotne konvekcije, na spoljašnjoj strani toplotno zračenje (sunčevo ir-zračenje - infra-crveno zračenje) može biti uzeto u proračun

zamenom spoljašnje temperature $T_{\text {out }} u(2)$ takozvanom sol-air temperaturom $T_{z a}$ koja se uzima za spoljašnju temperaturu vazduha, sunčevo zračenje i infra-crveno zračenje zida.

\subsection{Početni (inicijalni) uslovi}

Za rešavanje toplotne jednačine $u$ prelaznom stanju (1) potrebna je i inicijalna temperatura zida $\mathrm{za} t=0$ 


$$
\mathrm{T}(\mathrm{x}, 0)=\mathrm{T}_{0}(\mathrm{x})
$$

Inicijalna temperatura $T_{0}(x)$ koja će biti razmatrana je stabilno rešenje jednačine (1) sa konstantnim graničnim uslovima.

Vredno je napomenuti da je provereno u različitim simulacijama da drugi mogući inicijalni uslovi, kao što je konstantna temperatura (sa vrednošću izmedju maksimalne i minimalne spoljašnje temperature) za ceo zid ili linearna promena (od $\mathrm{T}_{\mathrm{in}}$ do $\mathrm{T}_{\max }$ ), imaju mali uticaj na karakteristike parametara toplotne energije navedene u narednom tekstu kada su najmanje dva kompletna perioda (dva dana) uzeta u razmatranje $u$ simulacijama.

\subsection{Parametri termičkih karakteristika zidova}

U termotehnici je definisano više različitih parametara za proračun termičkih karakteristika zidova. Koeficijent provodjenja toplote, poznat kao U-vrednost (inverzan termičkoj otpornosti) je standardna vrednost koja se koristi u propisima (i Eurokodu) za ocenu toplotne izolacije zidova (i uopšte, gradjevinskih elemenata) za stabilne toplotne režime. Ovaj parametar ne uzima u obzir efekat termičke inercije elemenata zidova i drugih gradjevinskih elemenata. Za promenljive spoljašnje temperature (dinamički režim) potrebna su još dva dodatna parametra (EN ISO 13786 (5)): dekrementni faktor i vremensko kašnjenje. Ova dva parametra definišu termalnu inerciju zida. Medjutim, ova dva parametra i računska procedura data u EN ISO 13786 (5) nisu direktno upotrebljiva za sisteme koji sadrže materijale sa promenom agregatnog stanja (PCM), što nije naš slučaj, već samo za zidove sa konstantnim termo-fizičkim osobinama (termalni kapacitet, termalna provodnost i gustina) u odgovarajućem temperaturnom opsegu.

Energija potrebna za nadoknadu gubitaka toplote kroz zid da bi se sačuvala odredjena unutrašnja temperatura, može se izračunati iz toplotnog fluksa na unutrašnjoj površini zida $\left(\mathrm{W} / \mathrm{m}^{2} \mathrm{~K}\right)$, što je dato na primeru proračuna ponašanja IZORETEKS-8-150-2.

\section{NUMERIČKO I SOFTVERSKO REŠENJE}

Diferencijalne toplotne jednačine (1) - (4) mogu se rešiti u zatvorenom obliku formulama dobijenim analitičkim metodama samo za jednostavne probleme. Za kompleksne slučajeve, proračun temperaturnog profila zida $T(x, t)$ zasniva se na korišćenju pogodnih numeričkih metoda za rešavanje ovih jednačina. Postoje različite numeričke formule (diskretizacije) kojima se konstruišu algoritmi koji se mogu realizovati na računarima radi rešavanja jednačina (1) - (4). Ovi algoritmi daju različite tačnosti proračuna i različita vremena izračunavanja. Algoritmi su implementirani na jeziku MATLAB, koristeći tri metode: FEM (Final Element Method), FV (Final Volume Method) i EF, tj. FEM zasnovan na definiciji entalpije (Enthalpy Formulation), radi uporedjivanja pouzdanosti tih metoda, tačnosti i računskog vremena.

Naglasimo da se MKE (FEM) metod može primeniti direktno za slučajeve u kojima karakteristike variraju sa položajem (na primer, višestruki slojevi koji se sastoje od 
Међународна конференција

Савремена достигнућа у грађевинарству 24. април 2015. Суботица, СРБИЈА

slojeva od različitih materijala) i temperaturom. Dakle, ovaj sistem diferencijalnih jednačina je uopšte nelinearan i može biti linearan samo kada su fizičke karakteristike $\left(\rho, c_{p}, k\right)$ i koeficijenti prenosa toplote graničnih uslova $\left(h_{i n}, h_{\text {out }}\right)$ temperaturno nezavisni.

Važno je podsetiti da su, usled lokalne definicije bazne funkcije konačnog elementa, matrice $\mathrm{M}, \mathrm{K}$ obe trodijagonalne, pa se mogu primeniti specifični i optimizirani algoritmi za rešavanje linearnih sistema tog tipa (iterativno rešenje trodijagonalnih sistema linearnih jednačina).

Postoje različite numeričke metode za rešavanje gore datog sistema diferencijalnih jednačina (ODE), kao što su Ojlerova metoda, metoda Runge-Kutta, itd. Ova FEM diskretizacija je realizovana u programu MATLAB, a rešavanje (integracija $u$ vremenskom domenu) je realizovana MATLAB funkcijama ode45 i ode15s, zavisno od kompleksnosti sistema. Prva funkcija je bazirana na eksplicitnoj Runge-Kutta metodi, a druga na adaptivnoj metodi nepoznatih koeficijenata na osnovu formula za numeričku diferencijaciju (NDF formule). Drugi mogući algoritam za rešavanje jednačina (1) - (4) je takozvana metoda konačne zapremine, Finite Volume (FV).

MATLAB programska okolina je korišćena za implementaciju numeričkih metoda i odgovarajučih algoritama prikazanih prethodno. MATLAB raspolaže sa više procedura za integraciju diferencijalnih jednačina. U ovom slučaju je korišćen vremenski integrator ode15s za retko posednute (SPARSE) matrice. Ova procedura omogućava implicitno veći vremenski interval koji omogućava brže izračunavanje. Pored toga, program može da oceni grešku proračuna u svakom koraku i da odluči da li je vremenski korak suviše veliki ili suviše mali, tj. korak integraljenja je adaptivan. Ova osobina je vrlo korisna za efikasan proračun kada su termo-fizičke osobine vrlo zavisne od temperature, što nije slučaj kod linearnih sistema koji su predmet našeg modeliranja.

Takodje, moguće je primeniti FEM diskretizaciju baziranu na definiciji entalpije (Enthalpy Formulation (EF)), kao nepoznatu u jednačinama razmene toplote,

$$
\mathrm{e}(\mathrm{T})=\int_{\mathrm{T}_{\mathrm{Tef}}}^{\mathrm{T}} c_{\mathrm{p}}(\mathrm{T}) \mathrm{dT}
$$

Jednačine izvedene koristeći definiciju entalpije mogu se takodje diskretizovati Metodom konačnih elemenata, na sličan način kao za termičku formulaciju.

Glavni nedostatak primene definicije entalpije je njena kompleksnost kada se primenjuje na višeslojne sisteme, usled graničnih uslova izmedju slojeva (neprekidnost temperature i toplotnog fluksa), koji nisu prirodni u ovoj formulaciji i moraju se definisati dodatnim jednačinama.

Za navedene metode, odgovarajuće MATLAB datoteke i funkcije su date u softverskom prilogu uz projekat IZORETEKS (Prilog A (FEM), Prilog B (FV) i Prilog C (EF), respektivno). Kako su primene ovih metoda slične, objašnjena je samo ona koja odgovara Konačnom volumenu (FV). Razlog izbora ove metode je taj što preliminarni uporedni testovi pokazuju da FV metod ima vrlo približne računarske performanse sa FEM i FV metodama, ali je pogodan za primenu kod izolacionih materijala sa nelinearnim ponašanjem termičkih karakteristika (termička provodnost, termički 
kapacitet), kao što je slučaj kod termičkog proračuna izolacije uz prisustvo materijala kod kojih dolazi do promene agregatnog stanja (PCM).

Predhodno navedene tri implementacije, FEM, FV i EH, su uporedjene iz aspekta računskih performansi, sa ciljem selekcije najefikasnije metode. Korišćena su dva kriterijuma: tačnost i računarsko vreme simulacije. U tu svrhu obavljen je niz testiranja. Benčmark test pokazuje da je diskretizacija koja koristi FV metod najbrža za unapred datu tačnost. Iako su razlike u računskom vremenu izmedju FV i FEM metoda male, u optimizacionom procesu, broj konfiguracija zidova koje treba izračunati je obično vrlo veliki, tako da se te male razlike mogu pokazati važnim za opšte smanjenje računskog vremena. Da bi se dobila tačnost "konvergentnog rešenja", računalo se sa vrlo finom mrežom (400 elemenata), što je korišćeno kao referenca. Za isti broj elemenata (mrežu) tačnosti su približne (FEM tačnost je blago bolja od ostala dva), ali su FEM i FV znatno brže od EF. Razlog može ležati u činjenici da adaptivna integracija (realizovano MATLAB ugradjenom funkcijom ode15s) u cilju EF diskretizacije zahteva više izračunavanja funkcije nego FEM i FV. Sa druge strane, glavni razlog zašto je FV brža od FEM izgleda da je to što je matrica masa $\mathbf{M}$ dijagonalna, pa je inverzija direktna, dok je kod FEM, matrica tro-dijagonalna.

\section{PRIMENA SOFTVERA ZA TERMIČKU IDENTIFIKACIJU}

Više konfiguracija različitih debljina, gustina i granulacija je podvrgnuto testiranju. Uzorci pod oznakom
Uzorak-1 (IZORETEKS125-8-1),
Uzorak-2 (IZORETEKS150-8-1),
Uzorak-5 (IZORETEKS135-5-1),
Uzorak-6 (IZORETEKS115-5-1),
Uzorak-7 (IZORETEKS100-5-2),

su podvrgnuti testiranju. Ulazni podaci se nalaze $u$ skriptu nazvanom Izoreteks_comparison, radi automatskog generisanja ulaznih podataka, a u cilju ispitivanja različitih kombinacija materijala. Na slikama 1,2 i 3 dati su primeri rezultata simulacionog softvera za poznate primere (borovina i betonski blok) i IZORETEKS-8$150-1$.

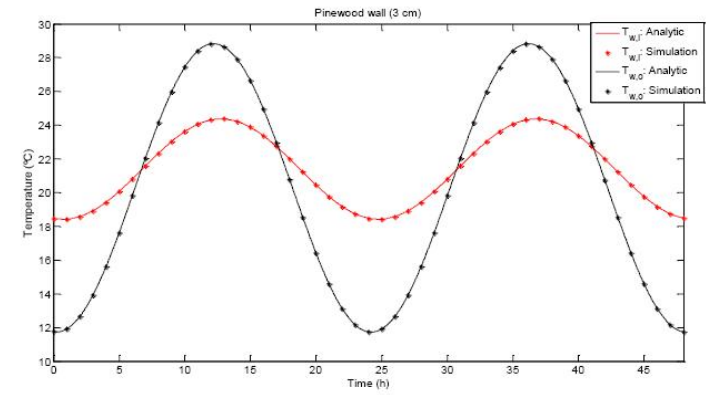

Slika 1: Uporedjenje temperatura površina zida računatih termičkim softverom $i$ analitičkim formulama. Test 3: Zid od borovog drveta debljine $3 \mathrm{~cm}$. 


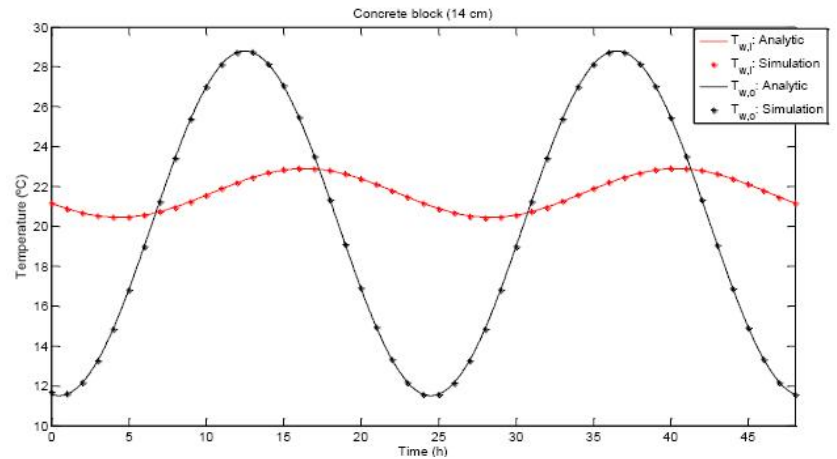

Slika 2: Uporedjenje temperatura površina zida računatih termičkim softverom $i$ analitičkim formulama. Test 2: Betonski blok debljine $14 \mathrm{~cm}$.

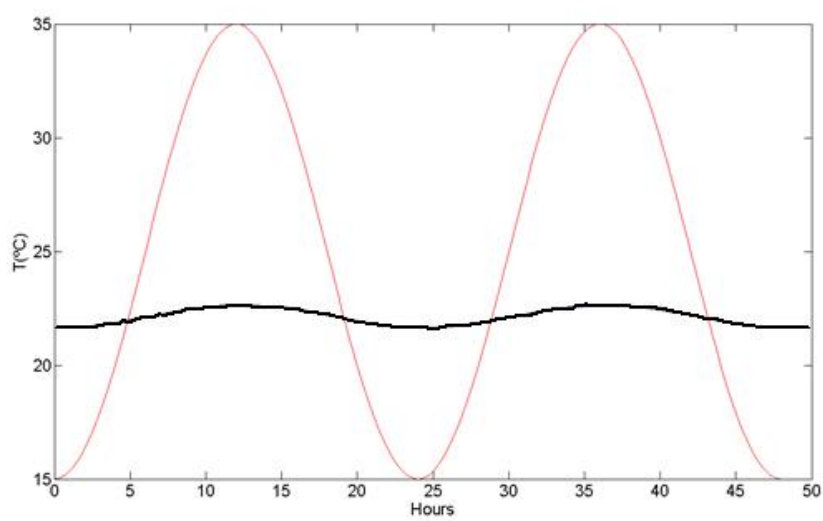

Slika 1: Temperatura površine unutrašnjeg zida za referentni slučaj IZORETEKS-8-1501 (150 kg/m3). Spoljna temperatura (crvena kriva) je takodje uključena da bi se videli "vremensko kašnjenje" $i$ "dekrementni faktor".

\section{ZAKLJUČAK}

- Tri različita numerička postupka, FEM, FV (Finite Volume) i Entalpija su predložena i primenjena za rešavanje jednačina provodjenja toplote za višeslojne zidove. Kao rezultat ovog istraživanje razvijen je softver baziran na metodi konačnog volumena (Finite Volume Method) i napisan kod u programu MATLAB.

- Razvijeni programski moduli su verifikovani na dva reprezentativna slučaja:

1) Monolitni zidovi sa konstantnim karakteristikama: validacija prema analitičkim rešenjima (EN ISO 13786: 2007 i formulama datim u ovom tekstu. 
2) Višeslojni zidovi i uporedjenje sa simulacijama komercijalnog softvera CFD (ANSYS CFX).

- Planirano je da se u daljem istraživanju rezultati provere eksperimentalnim merenjima i uporedjenjem sa rezultatima softverske simulacije (verifikacija matematičkih modela na kojima je zasnovana simulacija).

- Simulacije takodje pokazuju da su spoljačnje maksimalne i minimalne temperature, kao i unutrašnja temperatura važni parametri za izbor najpogodnijih izolacionih materijala za datu primenu. Položaj i dimenzije graničnih slojeva, kao i termalna otpornost susednih slojeva imaju takodje uticaj na termičke karakteristike celog višeslojnog sistema.

- Termički softverski paket, kao i akustički paket, deo su opštijeg paketa namenjenog za projektovanje i optimizaciju energetski efikasnih gradjevina korišćenjem novih izolacionih materijala.

- Termički softver koji je ovde koriščen je projektovan sa dovoljno fleksibilnosti tako da može biti modifikovan i proširen tako da simulira nove osobine (na primer, efekte podhladjenja) koje nisu raspoložive u sadašnjim paketima za termički proračun.

\section{LITERATURA}

[1] Patankar, S.V.: Numerical Heat Transfer and Fluid Flow.: Taylor and Francis, 1980.

[2] EN ISO 13786, 2007: Thermal performance of building components. Dynamic thermal characteristics. Calculation methods, 2007.

[3] Zienkiewicz, O.C. , Taylor, R. L.: The Finite Element Method, ButterworthHeinemann, 2000.

[4] Atkison, K.E., Ham,W., Stewart, D.: Numerical Solution of Ordinary Differential Equations, John Wiley \& Sons, 2009.

[5] L.F. Shampine, L.F, Gladwell, I., Thompson, S.: Solving ODEs with MATLAB, Cambridge University Press, 2003.

[6] Incropera, F.P, et al. : Fundamentals of Heat and Mass Transfer, Wiley, 2006.

[7] Threlked, J.L.: Thermal Environmental Engineering, Prentice-Hall, 1970.

[8] EN ISO 6946, 1996. : Building components and building elements. Thermal resistance and thermal transmittance. Calculation method. 1996. 
Међународна конференција

Савремена достигнућа у грађевинарству 24. април 2015. Суботица, СРБИЈА

\section{THERMAL CHARACTERIZATION OF NEW INSULATION MATERIAL - IZORETEX}

Summary: The Construction Cluster „DUNDJER“, together with a large number of its members, is participating, as a leading partner, in a national project co-financed by the National Agency for Regional Development, named IZORETEX. IZORETEX is a project which aims to develop a new thermal and acoustic insulation building material based on the recycling of waste from the automotive industry, specifically auto-textile waste. The provided research contains experiments with thermical, acoustic, vibrational and antiflamable characteristics of this insulation material. Thermical part of research contains numerical modeling of thermal characteristics, writing code for software support of thermical model, and laboratory testing of thermic characteristics. Currently, testings of this material are in progress that will hopefully confirm its thermal, acoustic and vibration performances.

Keywords: industrial waste, textile waste, auto-textile waste, building thermal insulation, energy efficiency. 